\title{
Viral Infections of the Central Nervous System: A Case-Based Review
}

\author{
Cecilia Big, MD; Lora A. Reineck, MD and David M. Aronoff, MD
}

\begin{abstract}
Three patients with viral infections of the central nervous system (CNS) were evaluated on an inpatient infectious diseases consultation service within a two-week period. These cases, caused by herpes simplex virus, varicella zoster virus and enterovirus, highlight the importance of viral pathogens in causing debilitating infections of the CNS and provide examples of the utility of molecular diagnostics in evaluating patients with encephalitis and meningitis.The importance of antiviral therapy is particularly underscored by these cases, as is the variability in response of patients to such agents.
\end{abstract}

Keywords: Acyclovir; Encephalitis; Herpes infections; Meningitis

iral infections of the central nervous system (CNS) are not uncommon occurrences in clinical practice; however, the incidence of these cases is not well defined. Patients usually present with clinical features of aseptic meningitis and/or encephalitis of varying degrees of severity. The outcomes are also variable, depending on unclearly defined host- and organism-specific factors, ranging from generally benign, in cases of aseptic meningitis, to severe with neurological sequelae and even death in patients with encephalitis. While the etiology of many cases remains unknown, an increasing number of positive viral identifications are made, particularly since the advent of molecular diagnostics. A specific therapy is unfortunately available for only a few viruses (eg, herpes viruses, human immunodeficiency virus), but efforts for finding the causative organisms remain important for management (and prognosis) of patients. Clinical and laboratory features common to particular viral etiologies can guide clinicians in identifying potential pathogens. The purpose of this article is to use clinical cases to review, for both primary care providers and acute care practitioners, diagnostic and therapeutic highlights of common viral CNS infections. The cases described in this report were evaluated within the same two-week period on a busy inpatient infectious diseases consultation service at a tertiary care, academic medical center.

\section{Case Presentations}

Case 1

A 56-year-old male with a history of recurrent, cryptogenic, aseptic meningitis presented in early November with one day of fever, chills, neck stiffness, and worsening headache. Physical examination was notable for an oral temperature of $103.2^{\circ} \mathrm{F}$ and heart rate of $121 \mathrm{bpm}$. He appeared uncomfortable but without frank nuchal rigidity, focal neurologic deficits, or rash. Laboratory tests revealed a normal white blood cell count, electrolytes, and renal function. Cerebral spinal fluid (CSF) studies revealed 34 red blood cells $/ \mathrm{mm}^{3}$, 154 white blood cells $/ \mathrm{mm}^{3} \quad(77 \%$ neutrophils, $12 \%$ lymphocytes, $10 \%$ histiocytes), glucose of $63 \mathrm{mg} / \mathrm{dL}$, protein of $82 \mathrm{mg} / \mathrm{dL}$, and a negative Gram stain (table 1). Blood, urine, and CSF cultures for bacteria, viruses, and fungi were negative. Computed tomography (CT) scan of the head revealed stable, mild, diffuse prominence of the ventricular system. In light of reported penicillin and cephalosporin allergies, the patient 
Table 1. Cerebrospinal fluid analysis in case patients.

\begin{tabular}{|c|c|c|c|c|c|c|}
\hline & $\begin{array}{l}\text { RBC, } \\
\text { cells/mm }{ }^{3} \\
(0)\end{array}$ & $\begin{array}{l}\text { WBC, } \\
\text { cells/mm } \\
(0-5)\end{array}$ & $\begin{array}{l}\text { Percent } \\
\text { neutrophils } \\
(0 \%)\end{array}$ & $\begin{array}{l}\text { Percent } \\
\text { lymphocytes } \\
(60-80 \%)\end{array}$ & $\begin{array}{l}\text { Glucose, } \\
\mathrm{mg} / \mathrm{dl} \\
(50-70)\end{array}$ & $\begin{array}{l}\text { Protein, } \\
\text { mg/dl } \\
(15-45)\end{array}$ \\
\hline Case 1 & 34 & 154 & 77 & 12 & 63 & 82 \\
\hline Case 2 & 0 & 120 & 4 & 64 & 53 & 106 \\
\hline Case 3 & 24 & 3 & 4 & 20 & 87 & 40 \\
\hline
\end{tabular}

Normal values/ranges are given in parentheses.

received empirical vancomycin, meropenem and acyclovir parenterally. The patient felt symptomatically improved by the next morning. Polymerase chain reaction (PCR) performed on the CSF for herpes simplex viruses I and II was negative, while PCR for enterovirus RNA was positive. In light of these results, antibiotics were discontinued, the patient was treated supportively, and discharged home without sequelae.

The patient's history of recurrent meningitis dated back approximately two years prior to this episode. He had two documented attacks of aseptic meningitis before this presentation, the most recent occurring in September. Details from the first attack were not available but the second episode, which was managed at another hospital, was similar in presentation to the current one. Spinal fluid at that time was not tested for enteroviruses, but studies revealed 16 red blood cells $/ \mathrm{mm}^{3}, 184$ white blood cells $/ \mathrm{mm}^{3}$ (19\% neutrophils, $52 \%$ lymphocytes, $29 \%$ histiocytes), glucose of $56 \mathrm{mg} / \mathrm{dL}$, protein of $69 \mathrm{mg} / \mathrm{dL}$, and a negative Gram stain. The patient developed chronic throbbing headaches after multiple lumbar punctures (LP) were performed following the initial aseptic meningitis. Later, both lumbar and thoracic CSF leaks were identified and thought to be the cause of the chronic headaches. These leaks were repaired with fibrin glue injections, resulting in improved symptoms.

\section{Case 2}

A 72-year-old man with polymyalgia rheumatica and giant cell arteritis treated with oral methotrexate $2.5 \mathrm{mg}$ weekly and oral prednisone $10 \mathrm{mg}$ daily presented with fatigue, mental status changes, and headache for 1 day. Physical examination was notable for a temperature of $101.9^{\circ} \mathrm{F}$ and blood pressure 185/94 mmHg. He was alert and oriented to person, place, and time; however, he was only able to answer simple questions. $\mathrm{He}$ had no nuchal rigidity, focal neurologic deficits, or rash. Laboratory tests revealed a normal white blood cell count, electrolytes, and renal function. CSF studies revealed 0 red blood cells $/ \mathrm{mm}^{3}, 120$ white blood cells $/ \mathrm{mm}^{3}$ (4\% neutrophils, $64 \%$ lymphocytes), glucose of $53 \mathrm{mg} / \mathrm{dL}$, protein of $106 \mathrm{mg} / \mathrm{dL}$, and a negative Gram stain (table 1). Repeat CSF studies at 72 hours showed 0 red blood cells $/ \mathrm{mm}^{3}$, 155 white blood cells $/ \mathrm{mm}^{3}$ (1\% neutrophils, $93 \%$ lymphocytes, $6 \%$ histiocytes), glucose of $64 \mathrm{mg} / \mathrm{dL}$, and protein of $104 \mathrm{mg} / \mathrm{dL}$. Blood, urine, and CSF cultures were negative. Head CT and chest radiograph were unremarkable. He was started empirically on ceftriaxone IV 1 g every 24 hours, vancomycin IV 1 g every
12 hours, ampicillin IV 2 g every 4 hours, and acyclovir 10 $\mathrm{mg} / \mathrm{kg}$ every 8 hours. Additionally, because of a history of Coccidiodes granulomatous lung disease, he was started on fluconazole. Magnetic resonance imaging (MRI) of the brain was unremarkable. The patient's CSF Coccidiodes antigen was negative but PCR for varicella zoster virus (VZV) was positive. He was continued on acyclovir while hospitalized. The patient's mental status returned to baseline over the course of 5 days. He was discharged home on valacyclovir $1 \mathrm{~g}$ orally three times daily for total duration of treatment of 3 weeks. The patient regained his mental status and had no long-term sequelae.

\section{Case 3}

An 86-year-old female with hypertension presented with mental status changes for 5 days. On the first day of her illness, she presented to a local emergency department complaining of nausea, diarrhea, throat pain, and dry emesis. Physical examination was notable for mild confusion and a noncontrasted CT scan of the head was unremarkable. She was diagnosed with a urinary tract infection and gastroesophageal reflux and discharged home with prescriptions for nitrofurantoin and ranitidine. Over the next few days, she developed increasing confusion, word-finding difficulties, and gait instability. She was brought to the emergency department. Physical examination was remarkable for a temperature of $103^{\circ} \mathrm{F}$ and blood pressure of 202/86 mmHg. She was oriented only to self, with word-finding difficulties and perseveration. She had no nuchal rigidity, focal motor or sensory neurologic deficits, or rashes. Laboratory tests revealed a white blood cell count of 15,000 cells $/ \mathrm{mm}^{3}$, sodium of $125 \mathrm{mmol} / \mathrm{L}$, and potassium of $2.7 \mathrm{mmol} / \mathrm{L}$. CSF studies revealed 24 red blood cells $/ \mathrm{mm}^{3}$, 3 white blood cells $/ \mathrm{mm}^{3}$ (4\% neutrophils, $20 \%$ lymphocytes, $76 \%$ histiocytes), glucose of $87 \mathrm{mg} / \mathrm{dL}$, protein of $40 \mathrm{mg} / \mathrm{dL}$, and a negative Gram stain (table 1). Blood, urine, and CSF cultures were negative. Head CT and chest radiograph were unremarkable. She was treated empirically with parenteral ceftriaxone $1 \mathrm{~g}$ every 24 hours and vancomycin $1 \mathrm{~g}$ every 24 hours. She was noted to be delirious, and parenteral acyclovir $10 \mathrm{mg} / \mathrm{kg}$ every 8 hours was begun approximately 48 hours after admission to treat for possible herpes simplex virus infection. Brain MRI revealed abnormal signal within the left temporal lobe (figure 1). PCR on CSF for herpes simplex virus 1 (HSV-1) was positive. Electroencephalogram (EEG) revealed left temporal periodic lateralized epileptiform discharges with no clinical correlation suggesting subclinical seizures. The patient 
Table 2. Common viral etiologies of CNS infections.

\begin{tabular}{lll}
\hline Virus & Disease & Diagnostic CSF test \\
\hline HSV1 & Herpes Encephalitis & PCR, culture \\
HSV2 & Recurrent Meningitis & PCR, culture \\
& (Mollaret) & PCR, culture \\
VZV & Large vessel vasculitis & \\
& (immunocompetent patient) & \\
& Small vessel vasculitis & PCR \\
Enteroviruses & (immunosuppresed patient) & West Nile Virus-specific IgM, \\
West Nile Virus & Aseptic meningtis & PCR \\
\hline
\end{tabular}

was started on levetiracetam and phenytoin to suppress epileptic activity. A 21-day course of IV acyclovir therapy was given. She has had gradual clinical improvement in her mental status. At 6 months, she continues to have residual expressive aphasia with some word finding and short-term memory difficulties.

\section{Discussion}

Viral infections of the CNS, though uncommon, are not rare. In a recent 7-year prospective observational study of 1570 patients with encephalitis, $248(16 \%)$ had a confirmed or probable cause identified. Of these, $170(69 \%)$ cases had a viral etiology, and the most frequently identified viruses were enterovirus, HSV-1, VZV and West-Nile virus. Other identified causes include bacterial (20\%), prion (7\%), parasitic $(3 \%)$, and fungal $(1 \%){ }^{1}$

Patients afflicted by these heterogeneous disorders often present acutely to their primary care providers or to acute care practitioners for evaluation. The cases described above and discussed below illustrate commonalities and distinctions between these two entities and underscore important clinical and diagnostic aspects of viral CNS infections in adults.

The initial approach to the patient with suspected CNS infection requires an early recognition of the meningitis and/or encephalitis syndrome, and needs to include a rapid diagnostic evaluation coupled with concurrent antimicrobial and adjunctive therapy (eg, corticosteroids, when indicated). Delay in the initiation of therapy introduces the potential for increased morbidity and mortality, such as in cases of acute bacterial meningitis and herpes encephalitis. ${ }^{3}$ It is also important to distinguish a true CNS infection from noninfectious causes of encephalopathy (such as hepatic, renal, or other metabolic encephalopathies). ${ }^{4}$ Additionally, it is important to note that the differential diagnosis of aseptic meningitis includes other infectious etiologies such as Mycobacterium tuberculosis, fungi and parasites, as well as non-infectious causes including malignancy, vasculitis and certain medications.

\section{Viral Etiologies of CNS Infections}

Viruses can cause meningitis or encephalitis, and the clinical presentation may overlap, with the latter having more significant alterations in the level of consciousness and possibly new psychiatric symptoms, cognitive defects, seizures, or focal neurologic deficits. ${ }^{2}$ The presentation of viral CNS infections is usually of a sudden onset of illness with fever, headache, nuchal rigidity, focal neurological signs, CSF pleocytosis, and focal abnormalities may be seen on EEG, $\mathrm{CT}$ and/or MRI. The diagnosis of meningitis or encephalitis is based upon which features predominate in the illness although meningoencephalitis is also a common term that recognizes the overlap. Distinguishing between encephalitis and meningitis is important because the likely etiology and subsequent management of each is different. ${ }^{2}$

A detailed history can provide clues for an etiologic diagnosis. ${ }^{3}$ Occurrence during summer suggests arbovirus (eg, West Nile virus) or enterovirus infection, while winter disease suggests other infections (eg, influenza). ${ }^{3}$ The travel history can reveal clues to geographically-restricted viruses, such as those predominantly found in Asia (Japanese encephalitis). Other points include taking a history of sexual contacts (eg, HIV), insect contact (eg, mosquitoes harboring Western and Eastern equine viruses, West Nile virus), animal contact (eg, rabies virus, lymphocytic choriomeningitis virus [LCMV]), recent vaccination or viral illness (eg, acute demyelinating meningoencephalitis); and immunosuppression (eg, human herpes virus 6, VZV, cytomegalovirus, or JC virus) (table 2).

On physical examination, patients often have fever and may have signs of meningeal irritation but clear sensorium (ie, meningitis), or altered mental status (ie, encephalitis). The skin examination provides additional information: a petechial rash suggests meningococcal meningitis; a maculopapular rash can occur with West Nile virus meningoencephalitis; 5 and a group of vesicles in a dermatomal pattern suggests VZV. 
A LP is important. Interpreting the results can be difficult, as there is overlap between the CSF findings in bacterial and viral infections, however broad general differences can be stated. ${ }^{2}$ In acute bacterial meningitis, CSF white cell counts are usually high (hundreds or thousands per $\mu$ l), with neutrophilic predominance, accompanied by elevated proteins and hypoglycorrachia; while in viral meningitis CSF shows a mild pleocytosis and lymphocytic predominance (though early it can be neutrophilic), slightly elevated protein, and normal glucose (except LCMV when glucose is low). ${ }^{2}$

Nucleic acid amplification methods have improved the detection of common (HSV, enterovirus, and VZV) and uncommon viral pathogens. The results of these tests are available more quickly and are more sensitive than viral cultures. Other viral causes of meningoencephalitis, such as arboviruses (including West Nile), can be identified by detection of $\mathrm{IgM}$ and $\mathrm{IgG}$ antibodies in $\mathrm{CSF}^{3}$

Imaging with $\mathrm{CT}$ scans alone can be done in uncomplicated cases of meningitis, but MRI should be considered for all patients with encephalitis. The MRI is generally useful for confirmation of diagnosis of encephalitis, and sometimes there are characteristic patterns on imaging that may suggest a particular etiology, such as edema and hemorrhage in the temporal lobes in patients with herpes simplex encephalitis. ${ }^{6}$ This finding was obvious in our third case (figure 1). Another neurodiagnostic test that should be considered in the diagnosis of viral encephalitis is the EEG, particularly in confused or obtunded patients who may have nonconvulsive seizure activity, as exemplified by our third case. ${ }^{3}$

\section{Enterovirus CNS Infections}

The first case presented above represents enterovirus meningitis. Approximately $26 \%$ of adult aseptic meningitis cases for which an etiologic agent is identified are caused by enteroviruses. ${ }^{7}$ These infections generally occur in the summer and fall, but can occur in any season, as in our first case that was diagnosed in November. The clinical picture is commonly difficult to distinguish from bacterial meningitis; therefore, patients are frequently hospitalized, empiric antibiotic are prescribed, and multiple diagnostic tests are done. The course of enteroviral meningitis is benign, and therapy is directed at symptomatic relief. The CSF enterovirus PCR has proven to be a sensitive test with great cost-saving capabilities, as those who test positive tend to have shorter hospital stays, fewer tests performed, and receive IV antibiotics for less time. ${ }^{8}$

\section{Varicella Zoster Virus Encephalitis}

Varicella zoster virus (VZV) encephalitis is an important cause of viral encephalitis, with mortality reported in up to $25 \%$ of cases. ${ }^{9}$ As exemplified by our second case, VZV has been associated with older age and with immunosuppression. It can present before, after, or in the absence of the dermatomal rash of shingles, making the clinical suspicion difficult in the latter case. In immunocompetent individuals, VZV causes largevessel vasculitis manifested as ischemic or hemorrhagic stroke,

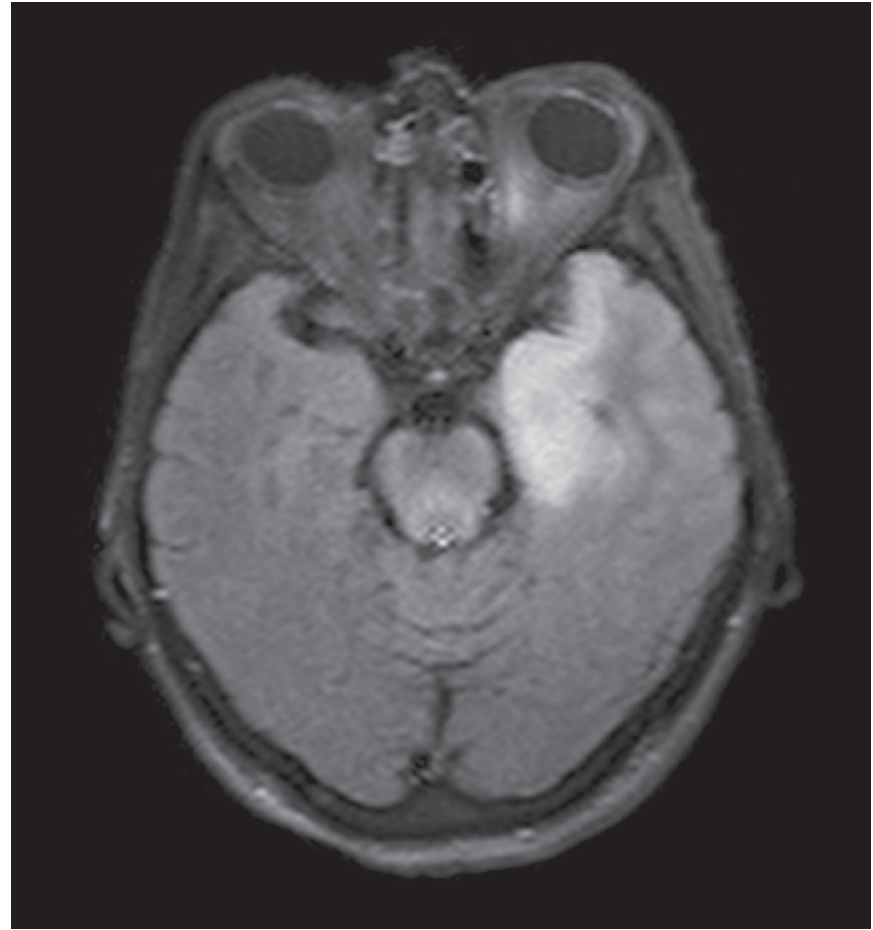

Figure 1. MRI (T2 image) of the brain shows enhancement in the left temporal lobe in Case 3.

generally weeks to months after herpes zoster ophthalmicus. In immunosupressed patients, VZV causes a multifocal small vessel vasculopathy. On imaging, it presents as ovoid, round lesions at the gray-white matter junction. PCR can detect VZV DNA in CSF, however, a negative test does not exclude the diagnosis of VZV encephalitis. ${ }^{3}$ IgM antibodies can sometimes be detected in CSF in such cases. Therapy with acyclovir $10 \mathrm{mg} / \mathrm{kg}$ every 8 hours is recommended for 10 to 14 days. ${ }^{3,10}$

\section{Herpes Simplex Encephalitis}

HSV-1 is the most common cause of viral encephalitis. Herpes simplex encephalitis (HSE) remains one of the most devastating infections of the central nervous system, with high morbidity and mortality despite available antiviral therapy. About half of treated patients die or are left with severe impairment. ${ }^{11}$ Clinical suspicion of HSE is suggested by encephalopathy and/or focal neurological symptoms in a febrile patient, but these are not specific. Imaging evaluation can provide support for the diagnosis by the demonstration of temporal lobe edema/hemorrhage on MRI (figure 1). The diagnostic gold standard is the detection of HSV DNA in the cerebrospinal fluid by PCR. The HSV PCR has been noted to have a high sensitivity, around $96 \%$ to $98 \%$. In cases with negative results but high clinical suspicion, the test should be repeated after 3 to 7 days, as the detection of virus may be difficult in the first few day of illness. ${ }^{3}$ Acyclovir is the treatment of choice and is administered at $10 \mathrm{mg} / \mathrm{kg}$ every 8 hours for 14 to 21 days. 3,11 Our case was initially thought to have an encephalopathy secondary to a urinary tract infection. HSE was only diagnosed 5 days after the onset of symptoms, 
which may have contributed to the severity of illness. This case illustrates the need for high clinical suspicion with concomitant therapy initiation pending laboratory confirmatory testing.

\section{Empirical Management}

Upon presentation, patients who are immunocompromised, have a history of CNS disease, papilledema, or focal neurologic deficits, should have a CT scan of the head prior to LP.

Patients with a clinical picture suggestive of meningitis should be investigated for the possibility of bacterial and viral causes (eg, enterovirus, HSV-2) for the purpose of establishing the diagnosis and potential avoidance of unnecessary hospitalization and/or antibiotic treatment. If there is concern for bacterial meningitis, therapy should not be delayed by waiting for final results of the diagnostic studies (CT scan and LP).

If clues for encephalitis are suggested by history (sudden onset of fever and encephalopathy), exam (seizures), or studies (red cells in CSF, temporal lobe involvement on imaging), empiric therapy with intravenous acyclovir $10 \mathrm{mg} / \mathrm{kg}$ every 8 hours needs to be initiated in all patients as soon as possible. ${ }^{3} \mathrm{An}$ MRI and EEG should also be performed in all patients with encephalitis. ${ }^{3}$ Rarely, brain biopsy is needed in patients with encephalitis of unknown etiology whose condition worsens in spite of therapy with acyclovir.

\section{Conclusion}

As exemplified by our cases presented above, viral CNS infections have a wide spectrum of causes and clinical presentations. The initial management of patients with encephalitis, besides the investigation for an etiology, should include IV acyclovir in an attempt to avoid poor outcome in case of HSV encephalitis. In elderly and immunocompromised patients, even in the absence of vesicular rash, VZV should be in the differential of causes of encephalitis, especially with available testing and therapy. Enteroviruses are known as important viral cause of aseptic meningitis and generally have a benign course. With the wide availability of molecular diagnosis and important management and prognostic implications of viral identification, testing should be considered in initial workup of such cases.

\section{References}

1. Glaser CA, Honarmand S, Anderson LJ, Schnurr DP, Forghani B, Cossen CK, Schuster FL, Christie LJ, Tureen JH. Beyond Viruses: clinical profiles and etiologies associated with encephalitis. Clin Infect Dis 2006;43:1565-1577.

2. Somand D, Meurer W. Central nervous system infections. Emerg Med Clin North Am. 2009;27:89-100, ix.

3. Tunkel AR, Glasser CA, Bloch KC, Sejvar JJ, Marra CM, Roos KL, Hartman BJ, Kaplan SL, Scheld WM, Whitley RJ, Infectious Diseases Society of America. The management of encephalitis: clinical practice guidelines by the Infectious Diseases Society of America. Clin Infect Dis 2008;47:303-327.

4. Kennedy PG. Viral encephalitis. J Neurol 2005;252: 268-272.
5. Alonto AM, Aronoff DM, Malani PN. West Nile virus meningitis in patient with common variable immunodeficiency. Emerg Infect Dis 2003; 9:1353-1354.

6. Maschke M, Kastrup O, Forsting M, Diener HC. Update of neuroimaging in infectious central nervous system disease. Curr Opin Neurol 2004;17:475-480.

7. Kupila L, Vuorinen T, Vainionpää R, Hukkanen V, Marttila RJ, Kotilainen P. Etiology of aseptic meningitis and encephalitis in an adult population. Neurology 2006;66:75-80.

8. Ramers C, Billman G, Hartin M, Ho S, Sawyer MH. Impact of a diagnostic cerebrospinal fluid enterovirus polymerase chain reaction test on patient management. JAMA 2000;283:2680-2685.

9. Hilt DC, Buchholz D, Krumholz A, Weiss H, Wolinsky JS. Herpes zoster ophthalmicus and delayed contralateral hemiparesis caused by cerebral angiitis: diagnosis and management approaches. Ann Neurol 1983; $14: 543-553$.

10. Dworkin RH, Johnson RW, Breuer J, Gnann JW, Levin MJ, Backonja M, Betts RF, Gershon AA, Haanpaa ML, McKendrick MW, Nurmikko TJ, Oaklander AL, Oxman MN, Pavan-Langston D, Petersen KL, Rowbotham MC, Schmader KE, Stacey BR, Tyring SK, van Wijck AJ, Wallace MS, Wassilew SW, Whitley RJ. Recommendations for the management of herpes zoster. Clin Infect Dis 2007;44 Suppl 1:S1-26.

11. Whitley RJ. Herpes simplex encephalitis: adolescents and adults. Antiviral Res 2006;71:141-148.

12. Nagel MA, Cohrs RJ, Mahalingam R, Wellish MC, Forghani B, Schiller A, Safdieh JE, Kamenkovich E, Ostrow LW, Levy M, Greenberg B, Russman AN, Katzan I, Gardner CJ, Häusler M, Nau R, Saraya T, Wada H, Goto H, de Martino M, Ueno M, Brown WD, Terborg C, Gilden DH. The varicella zoster virus vasculopathies: clinical, CSF, imaging, and virologic features. Neurology 2008;70:853-860.

13. Ziai WC, Lewin JJ 3rd. Update in the diagnosis and management of central nervous system infections. Neurol Clin 2008;26:427-468.

14. Glaser CA, Gilliam S, Schnurr D, Forghani B, Honarmand S, Khetsuriani N, Fischer M, Cossen CK, Anderson LJ; California Encephalitis Project, 1998-2000. In search of encephalitis etiologies: diagnostic challenges in the California Encephalitis Project, 1998-2000. Clin Infect Dis 2003;36:731-742.

15. Tunkel AR, Hartman BJ, Kaplan SL, Kaufman BA, Roos KL, Scheld WM, Whitley RJ. Practice guidelines for the management of bacterial meningitis. Clin Infect Dis 2004;39:1267-1284.

\author{
Author Affiliations \\ Cecilia Big, $M D^{*}+$; \\ Lora A. Reineck, $M D^{\dagger}$; \\ David M. Aronoff, $M D^{*} ;$; \\ Division of Infectious Diseases* \\ and Department of Internal Medicinet \\ University of Michigan Health System \\ Ann Arbor, Michigan
}

